\title{
Structural design inspired by beetle elytra and its mechanical properties
}

\author{
GUO Ce ${ }^{*}$, SONG WenWei \& DAI ZhenDong * \\ Institute of Bio-inspired Structure and Surface Engineering, Nanjing University of Aeronautics and Astronautics, Nanjing 210016, China
}

Received July 10, 2011; accepted October 27, 2011

On the basis of the microstructure of the cross-section of a beetle's elytra, three bio-inspired lightweight structures were designed and built from acrylonitrile butadiene styrene plastic with a three-dimensional printer. The mechanical properties of three lightweight structures were analyzed and compared employing the finite element method, and quasi-static compression experiments and a three-point bending test on the structure samples were carried out using an electronic universal testing machine to verify the effectiveness of the finite element method. The results show that all three bio-structures were lightweight and had excellent mechanical properties. In particular, the bio-structure with spherical holes and hollow columns perpendicular to the top and bottom surfaces best imitated the microstructure of the cross-section of the Cybister elytra and had the greatest specific strength/stiffness in compression and bending. Finally, a preliminary optimization design was obtained for this bio-structure to further improve its specific strength and specific stiffness to $31.82 \mathrm{kN} \mathrm{m} / \mathrm{kg}$ and $108.73 \mathrm{kN} \mathrm{m} / \mathrm{kg}$ respectively.

elytra, microstructure, bio-inspired lightweight structure, finite element analysis

Citation: Guo C, Song W W, Dai Z D . Structural design inspired by beetle elytra and its mechanical properties. Chin Sci Bull, 2012, 57: 941-947, doi: $10.1007 / \mathrm{s} 11434-011-4956-3$

Low weight and high strength are preferred properties of materials used for railways, ships, vehicles and aerospace structures. Statistically, savings of $\$ 300, \$ 3000$, or $\$ 30000$ may be made by trimming just 1 pound from the weight of civil aircraft, fighter aircraft, or satellites and space stations, respectively [1]. Since a fuel savings of $5 \%$ results from a vehicle weight reduction of $10 \%$, reducing weight is one of the most effective ways for the automobile industry to trim vehicle fuel consumption [1]. Additionally, a lightweight structure plays a role in reducing noise, reducing $\mathrm{CO}_{2}$ emissions and protecting the environment. Adopting lightweight alloys (e.g., Ti, Al, Mg-Li) and lightweight structures (e.g., honeycomb structure, folded structures, foam-like structures, and fiber-reinforced structures) is an oft-used technique to make material structures lighter, but the topology of lightweight structures is far from optimized. Almost all biomaterials on Earth are composites, and significant progress has been made in understanding the high toughness of bio-

*Corresponding authors (email: guozc@ nuaa.edu.cn; zddai@nuaa.edu.cn) logical nanocomposites from various points of view, including their hierarchical structures, the effects of the mechanical properties of a protein on stress redistribution and energy dissipation, protein-mineral interface roughness and reduction of stress concentration at a crack tip, and mineral bridges on the surface of mineral platelets [2]. The superior performance of many biomaterials inspires the design of advanced materials and structures with the properties of low weight, high intensity, and high damage resistance. The American Air Force has supported projects that use the beetle exoskeleton as a model of a fiber-reinforced composite with a high stiffness-to-weight ratio and projects that use the mollusc shell as a model of a laminated composite for high-impact-resistant metal matrix composites [3]. Ötzen investigated the microstructural basis of a reduced stress concentration around the primary nutrient foramen of the equine third metacarpus and applied it to design flight-vehicle structures [4-7].

Beetles are a large family in nature. During millions of years of evolution and adaptation, some beetles developed 
their forewings into elytra, which are composed of materials such as chitin fiber, collagen, and amylase, and are characterized by a rigid texture and a particular form whose primary purpose is to protect the body and wings beneath the elytra, maintain flight balance, and control swerving [8]. Because of the excellent mechanical properties of elytra, such as high intensity and toughness, anisotropy, and the ability to self-heal, they serve as good bionic objects, and inspire the design of optimized structures that are lightweight, reliable, highly efficient, energy saving, and easy to control when used for spacecraft or aircraft parts [9].

Many recent studies on elytra have focused primarily on the surface morphology [10-15], structural coloration [16], micro-structure [17-20], the mechanism of coupling between elytra [21,22], and measurement of the mechanical properties of elytra [23], while studies on elytra-inspired lightweight structural design, manufacture and mechanical analysis have been rarely reported. In this paper, on the basis of the microstructure of the cross-section of Cybister (Cybister tripunctatus Olivier) elytra, three bio-inspired lightweight structures were designed and built with a threedimensional (3D) printer, their mechanical properties were analyzed employing the finite element method, and samples were tested using an electronic universal testing machine. The results show that all three bio-structures are lightweight and have excellent mechanical properties. In particular, the biostructure with spherical holes and hollow columns perpendicular to the top and bottom surfaces best imitated the microstructure of the cross-section of the Cybister elytra and had the best mechanical properties. A preliminary optimum design was obtained for this bio-structure with the objective of maximizing the specific strength and specific stiffness.

\section{Mechanical properties and microstructure of the cross-section of Cybister elytra}

In nature, a beetle's elytrum is made of a typical lightweight biomaterial with high strength. According to references $[20,23]$, the Cybister elytra have a duty ratio (cavity area to elytra area) of about $22 \%$ and density of $0.89 \times 10^{3} \mathrm{~kg} / \mathrm{m}^{3}$, while their average hardness and Young's modulus are 0.48 and 8.21 GPa respectively, and their transverse and longitudinal tensile strengths are as high as $169.2 \pm 22.5$ and 194.5 $\pm 23.4 \mathrm{MPa}$ respectively. We know that a structure determines the mechanical properties, so the microstructure of the cross-section of Cybister elytra is of great interest to scientists. According to scanning electron microscopy observations, the elytra have a similar morphological structure in lateral and longitudinal cross-sections. Both cross-sections are composed of cavities, fiber bundles that connect inner layers to the outer cuticular layers and acting as bridge piers, several chitin fiber layers and a dense black epicuticle (Figure 1). The thickness of the epicuticle (a single chitin fiber layer), the average diameter of cavities and the inner diameter of the hollow bridge pier are 12, 2, 80-95 and 30-40 $\mu \mathrm{m}$, respectively. The cavities in the elytra effectively reduce the structure weight over a span of about $250 \mu \mathrm{m}$.

\section{Elytra-inspired lightweight structural design}

As the cavities and the hollow bridge piers are the main weight-reducing parts of elytra, three bio-inspired lightweight structures with cavities and hollow columns were designed (see Figure 2). Structure I (Figure 2(a)) is an imitation of the microstructure of the cross-section of elytra only in the lateral direction, and consists of long throughholes and hollow columns perpendicular to the top and bottom surfaces. Structure II (Figure 2(b)) consists of spherical holes and hollow columns perpendicular to the top and bottom surfaces to imitate the microstructure of the cross-section of elytra both in the lateral and longitudinal directions. Structure III (Figure 2(c)) consists of a honeycomb network and columns located on the nodes of the honeycomb-shaped polygon following the suggestion of Chen et al. [24] based
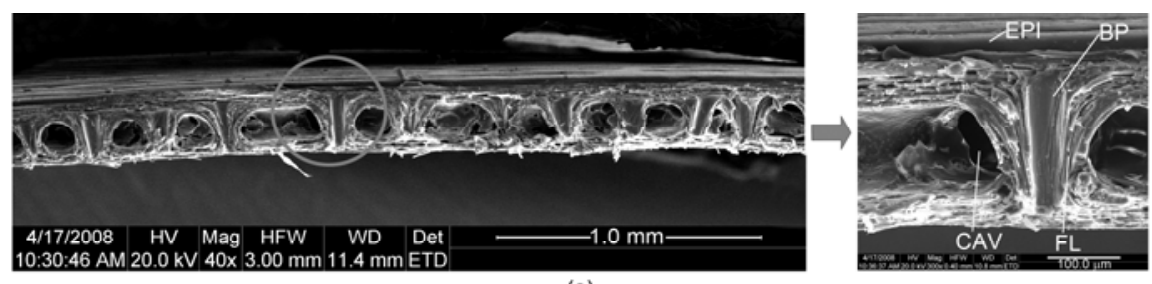

(a)

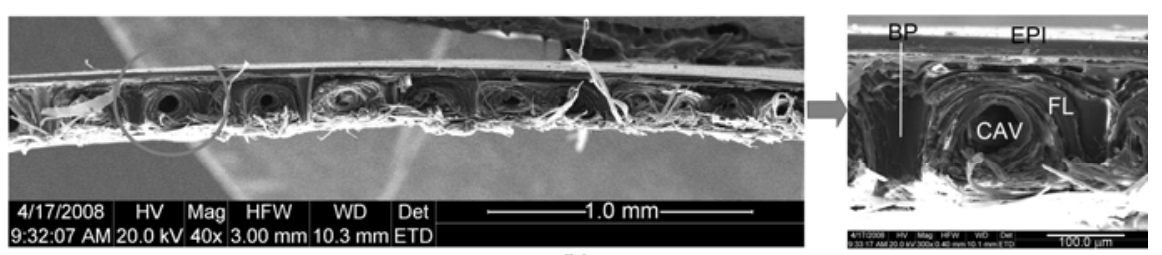

(b)

Figure 1 Microstructures of the lateral and longitudinal cross-sections of elytra. (a) Microstructure of the longitudinal cross-section of elytra; (b) microstructure of the lateral cross-section of elytra. EPI, Epicuticle; FL, Fiber layers; CAV, Cavity; BP, Bridge pier. 

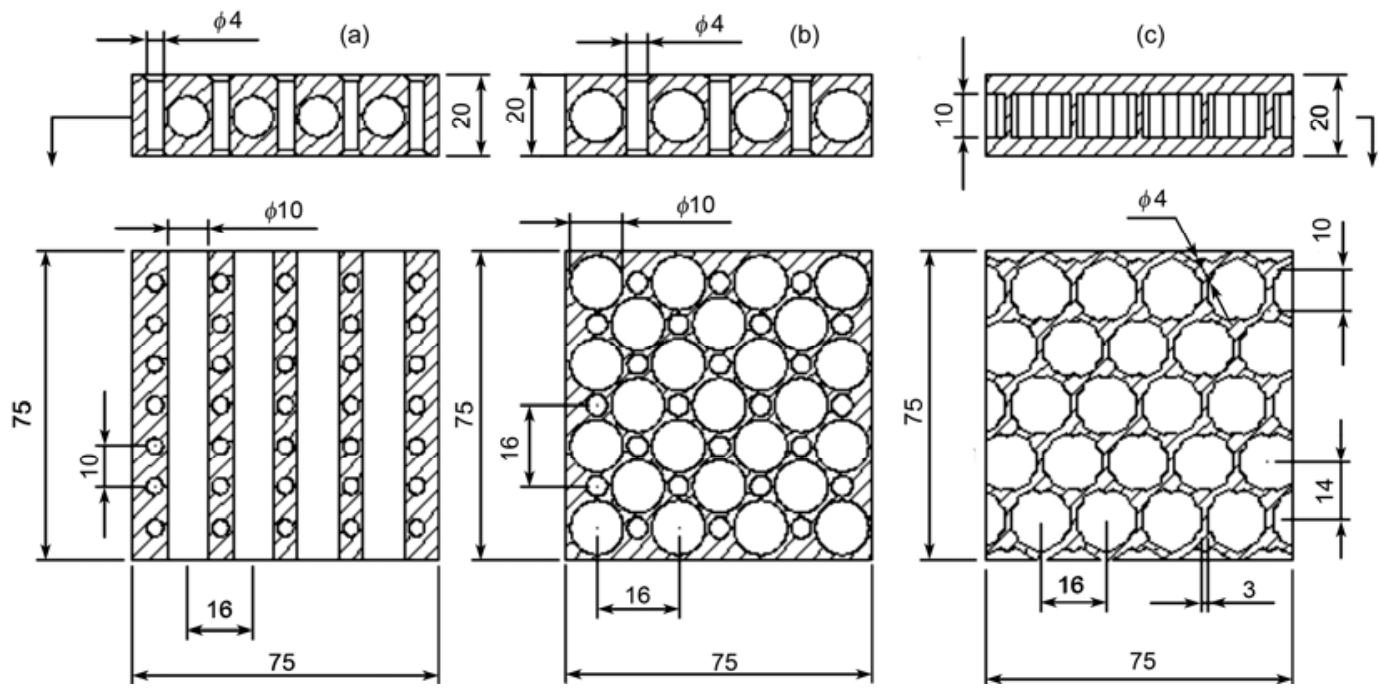

Figure 2 Bio-inspired lightweight structures (dimension unit, mm). (a) Structure I; (b) structure II; (c) structure Ш.

on the observation of the microstructure of the whole forewing of Allomyrina dichotoma.

\section{Mechanical analysis of bio-inspired structures}

Considering the possible application of the bio-inspired structures to the floorboards and body skeleton of subway trains and cars, the analysis mainly focused on the compressive and bending ability of the bio-inspired structures.

\subsection{Quasi-static compression analysis}

(1) Finite element modeling. 3D models of bio-structures were built with SolidWorks and then transferred into an ANSYS Workbench environment. The finite element type was Solid 186, and the total numbers of nodes and elements of three structures are given in Table 1. The main dimensions of the three structures were the same to allow comparison of the mechanical properties. The material of the models was acrylonitrile butadiene styrene (ABS) plastic, the same material used for structure samples built with a 3D printer. The material constants were set as density of $1.04 \times$ $10^{3} \mathrm{~kg} / \mathrm{m}^{3}$, Young's modulus of $1.2 \times 10^{3} \mathrm{MPa}$, Poisson's ratio of 0.3 and a yield limit of $22 \mathrm{MPa}$.

(2) Load and boundary constraints. Similar to the load and boundary constraints in the quasi-static compression experiment of the honeycomb structure [25], displacement

Table 1 Total numbers of nodes and elements of the bio-structures

\begin{tabular}{ccc}
\hline Finite element model & Total nodes & Total elements \\
\hline Structure I & 39474 & 23757 \\
Structure II & 23017 & 13300 \\
Structure III & 18130 & 10338 \\
\hline
\end{tabular}

was applied as a load to the top surface of the model step by step. Here, the number of load steps should be chosen reasonably. The model bottom was fixed for all six degrees of freedom (DOFs).

(3) Results analysis. To compare the compression strengths of the three structures, their compression forcedisplacement curves were determined as shown in Figure 3. The results show that for all three structures, the compression force initially changed linear elastically with the displacement. However, when the compression force reached the critical yield limit, the force changed little as the displacement continued to increase, demonstrating the structure had already reached the elastic-plastic stage. The stress corresponding to displacement of $2 \mathrm{~mm}$ was defined as the compression strength of the structure [26]. Taking the average density of the structures into account, the specific strength of the three structures were obtained (Table 2). It is seen that the compression strength and specific compression strength of structure II were the greatest. Given straight-line fitting of the linear part of the curve, the linear slope $K$ (i.e., the stiffness of the structure) could be obtained, which divided by its average density, gave the specific stiffness of the structure (Table 2). The results show that the stiffness and specific stiffness of structure II were the greatest, suggesting structure II has the best ability to resist compression deformation.

\subsection{Three-point bending analysis}

The bending strength of the three structures was analyzed and compared employing the finite element method, and the abilities of the structures to resist bending deformation were further computed. At the same time, a three-point bending test was performed to prove the reliability of the finite element method.

(1) Finite element modeling. As mentioned in Section 


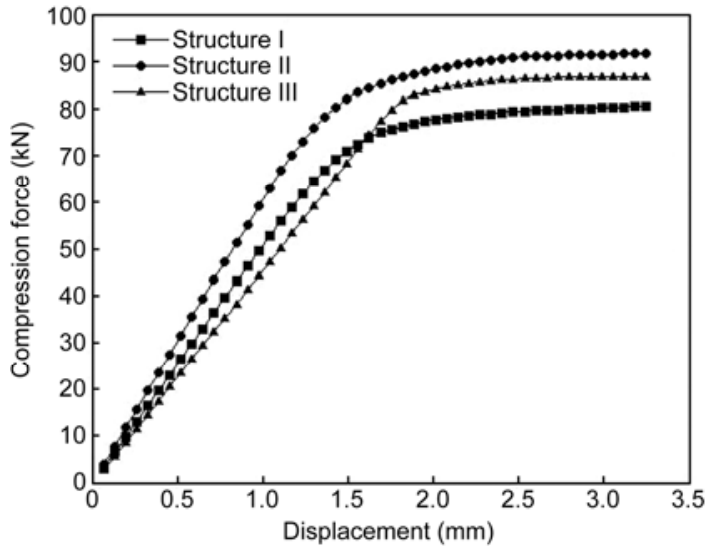

Figure 3 Compression force-displacement curves of the three structures.

Table 2 Specific compression stiffness and specific compression strength of the three structures

\begin{tabular}{|c|c|c|c|}
\hline Items & Structure I & Structure II & Structure III \\
\hline Stiffness (N/m) & $5.09 \times 10^{7}$ & $6.08 \times 10^{7}$ & $4.54 \times 10^{7}$ \\
\hline Average density $\left(\mathrm{kg} / \mathrm{m}^{3}\right)$ & $0.69 \times 10^{3}$ & $0.68 \times 10^{3}$ & $0.66 \times 10^{3}$ \\
\hline $\begin{array}{l}\text { Specific compression } \\
\text { stiffness }\left(\mathrm{kN} \mathrm{m}^{2} / \mathrm{kg}\right)\end{array}$ & 73.77 & 89.41 & 68.79 \\
\hline Compression strength (MPa) & 13.78 & 15.91 & 14.93 \\
\hline $\begin{array}{l}\text { Specific compression } \\
\text { strength }(\mathrm{kN} \mathrm{m} / \mathrm{kg})\end{array}$ & 19.97 & 23.40 & 22.62 \\
\hline
\end{tabular}

3.1, 3D models of the structures were imported into the ANSYS Workbench environment from SolidWorks (see Figure 4). The finite element type was again Solid 186. The total numbers of nodes and elements of the three structures are given in Table 3. The dimensions of the three models were $120 \mathrm{~mm} \times 30 \mathrm{~mm} \times 20 \mathrm{~mm}$. The wide side of the model section was chosen as the supporting side, the pressure head and the two supports were designated as rigid bodies,

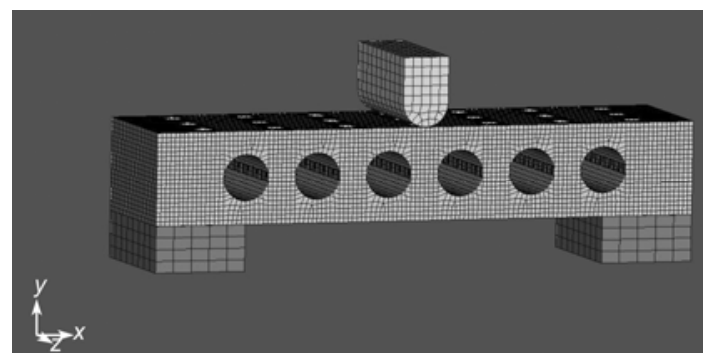

Figure 4 Finite element model in the three-point bending analysis.

Table 3 Total numbers of nodes and elements of the bio-structures

\begin{tabular}{ccc}
\hline Finite element model & Total nodes & Total elements \\
\hline Structure I & 37566 & 27576 \\
Structure II & 28008 & 15999 \\
Structure III & 25130 & 11833 \\
\hline
\end{tabular}

and the span of the two supports was $80 \mathrm{~mm}$. The material of the models was again ABS plastic.

(2) Constraints and contact definition. The nodes of the two supports were fixed for all six DOFs, and the nodes of the pressure head could only move vertically (in the $Y$ direction), with the other five DOFs being constrained. Following [27], the contact between the structural model and supports and that between the structural model and the pressure head were defined as being frictionless.

(3) Results analysis. To compare the bending strengths of the three structures, the reaction force and the displacement produced at the pressure head were determined to plot the bending force-displacement curve (Figure 5). It was shown that for all three structures, the bending force initially changed almost linearly until it reached the critical buckling limit and then began to decrease, demonstrating the collapse of cavities in the structure. Given the straight-line fitting of the linear part of the curve, the linear slope K (i.e., the bending stiffness of the structure) was obtained, which divided by its average density gave the specific bending stiffness of the structure (Table 4). The results show that the stiffness and specific stiffness of structure II were the greatest, suggesting structure II had the best ability to resist bending deformation.

Here, the stress corresponding to the maximum bending force was defined as the bending strength of the structure. Taking the average density of the structure into account, the

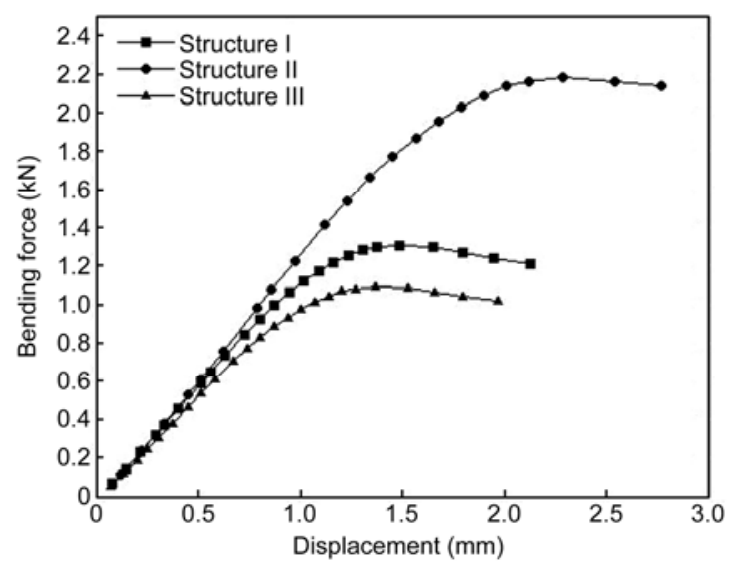

Figure 5 Bending force-displacement curves of three structures.

Table 4 Specific bending stiffness and specific bending strength of the three structures

\begin{tabular}{|c|c|c|c|}
\hline Items & Structure I & Structure II & Structure III \\
\hline Bending stiffness (N/m) & $1.17 \times 10^{6}$ & $1.26 \times 10^{6}$ & $1.02 \times 10^{6}$ \\
\hline Average density $\left(\mathrm{kg} / \mathrm{m}^{3}\right)$ & $0.69 \times 10^{3}$ & $0.68 \times 10^{3}$ & $0.66 \times 10^{3}$ \\
\hline $\begin{array}{l}\text { Specific bending } \\
\text { stiffness }\left(\mathrm{kN} \mathrm{m}^{2} / \mathrm{kg}\right)\end{array}$ & 1.70 & 1.85 & 1.55 \\
\hline Bending strength (MPa) & 16.35 & 27.25 & 13.62 \\
\hline $\begin{array}{l}\text { Specific bending } \\
\text { strength }(\mathrm{kN} \mathrm{m} / \mathrm{kg})\end{array}$ & 23.70 & 40.07 & 20.64 \\
\hline
\end{tabular}


specific strength of the structure can be obtained. From Table 4 , it is seen that the bending strength and specific bending strength of structure II were the greatest.

\section{Mechanical tests of bio-inspired lightweight structures}

\subsection{Manufacture of bio-inspired lightweight structures}

Considering the structural complexity of the models and the convenience and speed of building the models, three structural samples were built with a 3D printer (FDM 360mc, USA; the raw material used was ABS plastic). The dimensions were the same as for the finite element models (Figure 6). Here, mechanical tests were performed on an electronic universal testing machine (Shenzhen, China), and the results were used to verify the analysis results of the finite element method.

\subsection{Mechanical tests of bio-inspired lightweight struc-} tures

A quasi-static compression experiment and a three-point bending test were performed on an electronic universal testing machine with load changing between 0 and $10^{5} \mathrm{~N}$. The quasi-static compression is a single-direction force produced by moving the pressure head with a constant velocity of $1 \mathrm{~mm} / \mathrm{min}$. The force produced on the pressure head and the displacement due to the compression deformation of the sample were recorded and monitored by sensors. For the three-point bending test, the structural sample was fixed with the wide side of the section on the supports. The span was set as $80 \mathrm{~mm}$. Similarly, the pressure head moved with a constant velocity of $1 \mathrm{~mm} / \mathrm{min}$ at the middle of the span, and the force and the corresponding displacement of the pressure head were also recorded by sensors. Figures 7 and 8 compare the experimental results with the finite element method analysis results. Although there is a difference between the experimental and analytical results in Figure 8 (i.e., the force indicated by the experimental curve sharply declined after reaching a maximum owing to structural fracture, while the force indicated by the analytical curve declined gently), it is seen that the experimental results are in good accordance with the analysis results in the linear-elastic stage for both quasi-static compression and three-point bending, demonstrating the effectiveness and reliability of the finite element method analysis.

\section{Parameter optimization of the bio-inspired lightweight structure}

According to the analysis above, structure II has the best mechanical properties in compression and bending, and its structure is the closest to the microstructure of the crosssection of the Cybister elytra. Therefore, it was chosen as
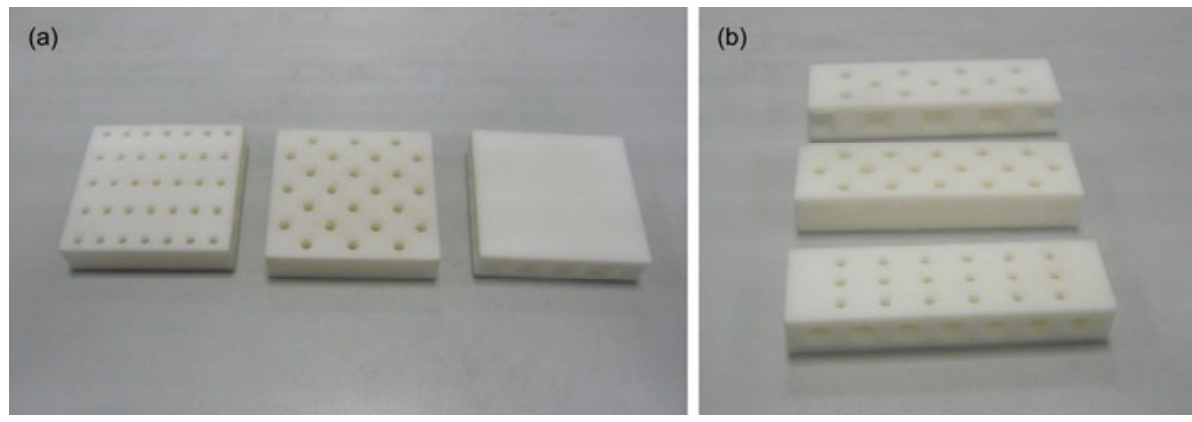

Figure 6 Bio-inspired lightweight structural samples built with a 3D printer. (a) Samples built for the quasi-static compression experiment; (b) samples built for the three-point bending test.
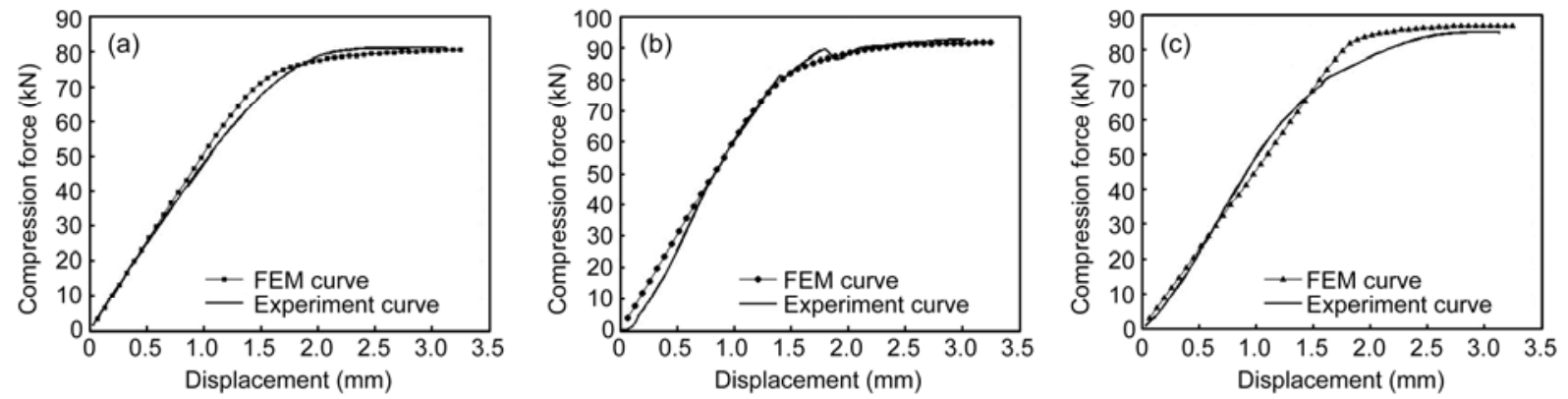

Figure 7 Quasi-static compression experimental results and finite element method results. (a) Structure I; (b) structure II; (c) structure III. 

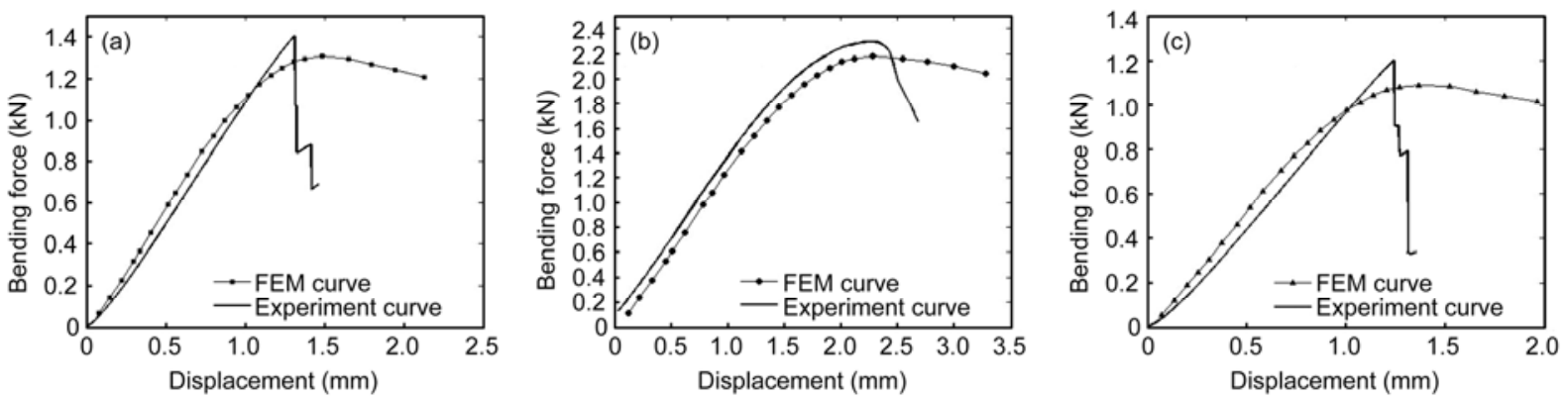

Figure 8 Three-point bending test results and finite element method results. (a) Structure I; (b) structure II; (c) structure III.

the model for further parameter optimization. Here, the preliminary optimized design was obtained under the assumption that the structure is only subjected to a compression force. The optimization objective is maximum specific strength and maximum specific stiffness. The design variables and constraints are given in Figure 9 and Table 5. The optimization design was obtained using DesignXplorer in ANSYS Workbench. The optimum results are presented in Table 6.

It is seen that, through optimization design, the specific strength of bio-structure II increased $35.9 \%$ to $31.82 \mathrm{kN} \mathrm{m} / \mathrm{kg}$, which is much higher than the values of $4-16 \mathrm{kN} \mathrm{m} / \mathrm{kg}$ for stainless-steel hollow-sphere foam and $\mathrm{Al}$ foam [28]. At the same time, its specific stiffness increased $21.6 \%$ to 108.73 $(\mathrm{kN} \mathrm{m} / \mathrm{kg})$.

\section{Conclusions}

(1) Cybister elytrum is an ideal biomimetic model for designing lightweight structures with higher specific intensity/specific stiffness. In this paper, three bio-inspired lightweight structures were designed and manufactured.

(2) The mechanical properties of bio-inspired lightweight structures were analyzed effectively employing the finite element method and tested using an electronic universal testing machine. The reliability of analysis results was demonstrated in mechanical tests.

(3) With parameter optimization, the compressive mechanical properties of the bio-inspired lightweight structure improved dramatically. The specific strength reached 31.82 $\mathrm{kN} \mathrm{m} / \mathrm{kg}$, which is much higher than that of stainless-steel hollow-sphere foam and Al foam. The specific stiffness increased to $108.73 \mathrm{kN} \mathrm{m} / \mathrm{kg}$. The maximum stress decreased from 22.47 to $13.11 \mathrm{MPa}$.
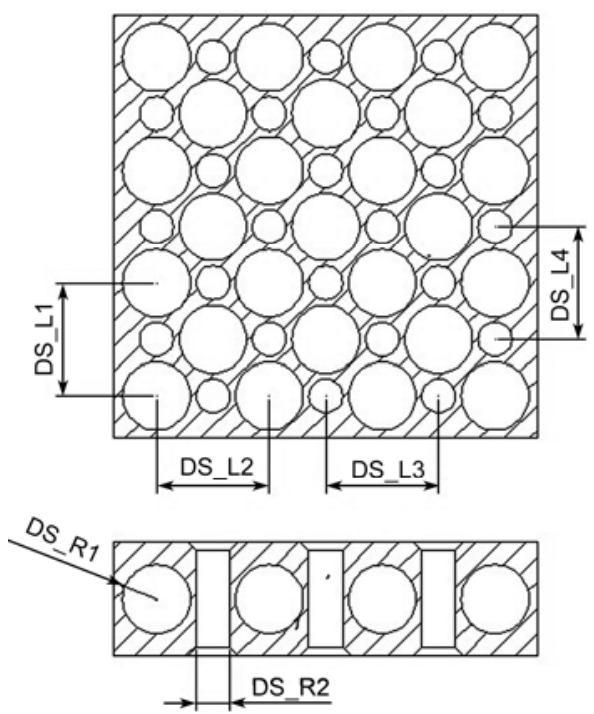

Figure 9 Structure II and chosen parameters.

Table 5 Variables and constraints (mm)

\begin{tabular}{cccc}
\hline Variables & Minimum & Maximum & Original value \\
\hline DS_R1 & 3 & 8 & 6 \\
DS_L1 & 18 & 22 & 20 \\
DS_L2 & 18 & 22 & 20 \\
DS_R2 & 2 & 5 & 3 \\
DS_L3 & 18 & 22 & 20 \\
DS_L4 & 18 & 22 & 20 \\
\hline
\end{tabular}

Table 6 Optimum results

\begin{tabular}{|c|c|c|c|c|c|c|}
\hline Parameters & DS_R1 & DS_L1 & DS_L2 & DS_R2 & DS_L3 & DS_L4 \\
\hline Initial value (mm) & 6 & 20 & 20 & 3 & 20 & 20 \\
\hline Optimization value (mm) & 4.14 & 19.69 & 19.95 & 4.31 & 18.09 & 18.02 \\
\hline Optimization results & \multicolumn{2}{|c|}{ Stress maximum (MPa) } & \multicolumn{2}{|c|}{ Specific strength $(\mathrm{kN} \mathrm{m} / \mathrm{kg})$} & \multicolumn{2}{|c|}{ Specific stiffness $\left(\mathrm{kN} \mathrm{m}^{2} / \mathrm{kg}\right)$} \\
\hline Initial value & \multicolumn{2}{|c|}{22.47} & \multicolumn{2}{|c|}{23.40} & \multicolumn{2}{|c|}{89.41} \\
\hline Optimization results & \multicolumn{2}{|c|}{13.11} & \multicolumn{2}{|c|}{31.82} & \multicolumn{2}{|c|}{108.73} \\
\hline
\end{tabular}


This work was supported by the National Basic Research Program of China (2011CB302106), the National Natural Science Foundation of China (51175249, 30770285), the Major Research Plan of the National Natural Science Foundation of China (90916021), and the Jiangsu Natural Science Foundation (BK2009376).

1 Dai Z D, Zhang Y F, Liang X C, et al. Coupling between elytra of some beetles: Mechanism, forces and effect of surface texture. Sci China Ser C-Life Sci, 2008, 51: 894-901

2 Chen C Q, Cui J Z, Duan H L, et al. Perspectives in mechanics of heterogeneous solids. Acta Mech Solida Sin, 2011, 24: 1-26

3 Winfield D L, Hering D H, Cole D. Engineering derivatives from biological systems for advanced aerospace applications. NASA CR177594. 1991

4 Ötzen N G, Cross A R, Ifju P G, et al. Understanding stress concentration about a nutrient foramen. J Biomech, 2003, 36: 1511-1521

5 Garita B, Rapoff A J. Biomimetic designs from bone. Exp Tech, 2003, 27: 36-39

6 Huang J H, Rapoff A J, Haftka R T. Attracting cracks for arrestment in bone-like composites. Mater Design, 2006, 27: 461-469

7 Huang J H, Haftka R T. Optimization of fiber orientations near a hole for increased load-carrying capacity of composite laminates. Struct Multidisc Optim, 2005, 30: 335-341

8 Chen B, Peng X H, Fan J H. Round-hole-fiber distribution in insect cuticle and biomimetic research. JSME Int J Ser C, 2004, 47: $1128-1132$

9 Dai Z D, Wang W Y, Zhang Y F, et al. Applications in outer space explore about the structure, height, intensity and topology of the beetle's exoskeleton (in Chinese). In: The Conference of the Outer Space Explore Technology and the Science Subject, Beijing, 2005. 68-72

10 Zhang Y C, Hai S W, Zhang J X, et al. A study on dorsal surface of Dactylispa (Tr.) angulosa with SEM (in Chinese). J Shanxi Normal Univ (Nat Sci Ed), 2001, 29: 70-73

11 Zhang Y C, Zhang Y, Zheng Z M. A comparative study on elytral ultrastructures in beetles of four species (in Chinese). J Northwest Univer (Nat Sci Ed), 2001, 31: 522-524

12 Chen J X, Ni Q Q. Three dimensional composite structures in the forewing of beetles (in Chinese). Acta Mater Comp Sin, 2003, 20: 61-66

13 Chen B, Peng X H, Fan J H. Fiber-reinforced characteristics of chafer cuticle and research on structure of branched fiber (in Chinese). Chin J Mater Res, 2003, 17: 630-636

14 Cheng H, Sun J R, Ren L Q, et al. Structure of the integumentary surface of the dung beetle Copris ochus Motschulsky and its relation to non-adherence of substrate particles (in Chinese). Acta Entomolo Sin, 2002, 45: 175-181

15 Holleway B A. Elytra surface structures as indicators of relationships in stag beetles, with reference to the New Zealand species (Coleoptera,Lucanidae). New Zealand J Zoology, 1997, 24: 51-63

16 Liu F, Yin H W, Dong B Q, et al. Inconspicuous structural coloration in the elytra of beetles Chlorophila obscuripe-nnis (Coleoptera). Phy Rev, 2008, 77: 901-904

17 Breed R S, Ball E F. The interlocking mechanisms which are found in connection with the elytra of Coleoptera. Biol Bull, 1909, 6: 289-303

18 Gorb S N, Rolf G B, Kastner V, et al. Structural design and biomechanics of friction-based releasable attachment devices in insects. Integ Comp Bio, 2002, 42: 1127-1139

19 Yu Q Q, Wang W Y, Yang Z X, et al. Study on the microstructure of cybister elytra and its mechanical properties (in Chinese). Prog Nat Sci, 2006, 16: 365-369

20 Yang Z X, Wang W Y, Yu Q Q, et al. Measurements on mechanical parameters and studies on microstructure of elytra in beetles (in Chinese). Acta Mater Comp Sin, 2007, 24: 92-98

21 Gorb S N, Goodwyn P J. Wing-locking mehanisms in aquatic heteroptera. J Morpho, 2003, 257: 127-146

22 Goodwyn P J, Gorb S N. Attachment forces of the hemelytra-locking mechanisms in aquatic bugs (Heteroptera: Belostomatidae). J Insect Physio, 2003, 49: 753-764

23 Yang Z X, Dai Z D, Guo C. Morphology and mechanical properties of cybister elytra. Chin Sci Bull, 2010, 55: 771-776

24 Chen J X, Ni Q Q, Li Q, et al. Biomimetic light weight composite structure with honeycomb-trabecula (in Chinese). Acta Mater Comp Sin, 2005, 22: 103-108

$25 \mathrm{Xu} \mathrm{Y} \mathrm{J,} \mathrm{Li} \mathrm{M,} \mathrm{Zhan} \mathrm{S,} \mathrm{et} \mathrm{al.} \mathrm{Tensile} \mathrm{and} \mathrm{compressing} \mathrm{properties}$ study of honeycomb structure by indoor testing and numerical analysis (in Chinese). Res Expl Labor, 2007, 26: 222-225

26 Lu Z X, Chen X, Zhang J L. Numerical modeling of high strain compression of anisotropic elastic open-cell foams (in Chinese). J Beijing Univ Aeronaut Astronaut, 2008, 34: 564-567

27 Xie Z Y, Li J R, Yu J L. Numerical simulation of three-point bending experiments of thin-walled cylindrical tubes filled with aluminum foam (in Chinese). Chin J Solid Mech, 2007, 28: 261-265

28 Rabiei A, Vendra L J. A comparison of composite metal foam's properties and other comparable metal foams. Mater Lett, 2009, 63: 533-536

Open Access This article is distributed under the terms of the Creative Commons Attribution License which permits any use, distribution, and reproduction in any medium, provided the original author(s) and source are credited. 